\title{
Analysis of the relationship between fetal magnetic resonance imaging indications and findings with ultrasonographic examination
}

\author{
Burak Akselimø, Süleyman Serkan Karaşin®, Beril Şenkutlu Kuyucu®
}

Department of Obstetrics and Gynecology, University of Health Sciences, Bursa Yüksek İhtisas Training and Research Hospital, Bursa, Turkey

\section{ABSTRACT}

Objectives: We aimed to examine the indications for the use of fetal MRI in obstetrics practice and the relationship between fetal MRI and ultrasonographic findings.

Methods: Seventy-three patients were examined with Fetal MRI for various reasons between July 2017 and July 2020, and whose results were available were evaluated retrospectively. Ultrasonographic and MRI findings were recorded. The detected pathologies were divided into groups according to systems. The relationship between the findings was examined.

Results: In our study, ultrasonographic findings of fifty-five (75.3\%) cases were confirmed by MR findings. MRI detected additional findings in eight (10.9\%) cases, most of which were intracranial pathologies. The most detected ultrasonographic findings as an indication for the request were in the intracranial region (54.8\%). Conclusions: Fetal MRI indications in perinatal care and follow-up are not clear. Determining these indications is also essential in preventing unnecessary use in obstetric practice and determining the cost-effectiveness.

Keywords: Fetal MRI, fetal ultrasonography, prenatal diagnosis, congenital anomalies

$\mathrm{U}$ ltrasonography is the first step diagnostic method in the diagnosis and screening of fetal anomalies [1]. Reliability, easy accessibility, cheapness, real-time imaging are the beneficial aspects of ultrasonography. However, ultrasonography may not always be sufficient to detect fetal anomalies mainly due to maternal obesity, oligohydramnios, fetal position. In such cases, fetal magnetic resonance imaging (MRI) comes into prominence to clarify the ultrasonographic diagnosis or to detect the presence of additional anomalies [2, 3]. MRI is also useful in detecting placental invasion anomalies.
In parallel with the development of MRI techniques, the artifact of fetal mobility is minimized by obtaining the image concisely. In parallel with this, fetal MRI as a complement to ultrasonographic findings has increased in recent years. It is challenging to determine fetal MRI indications due to experience and regional differences in perinatal management. It varies according to the individual pathology studied [2].

In this study, we aimed to evaluate the relationship between ultrasonography and MRI findings and fetal MRI indications in the diagnosis and screening of fetal anomalies.

How to cite this article: Akselim B, Karaşin SS, Şenkutlu Kuyucu B. Analysis of the relationship between fetal magnetic resonance imaging indications and findings with ultrasonographic examination. Eur Res J 2021;7(3):265-269. DOI: 10.18621/eurj.899462

Address for correspondence: Burak Akselim, MD., University of Health Sciences, Bursa Yüksek Ihtisas Training and Research Hospital, Department of Obstetrics and Gynecology, Mimarsinan Mah., Emniyet Cd., No: 35, 16310 Ylldırım, Bursa, Turkey.E-mail: burakakselim@hotmail.com, Tel: +90 2242955000 , Fax: +902242756767 


\section{METHODS}

This retrospective study was conducted by including 75 patients admitted to our tertiary hospital between July 2017 and July 2020 and underwent fetal MRI imaging for various indications. The study was approved by the Bursa Yüksek İhtisas Training and Research Hospital Ethics Committee (2011-KAEK-25 2020/06-22).

Demographic, clinical, ultrasonographic, MRI and delivery data were obtained from electronic patient records. MRI request indications were recorded. Pathological conditions detected as a result of the examination were divided into groups according to organ systems. Ultrasonography and MRI findings were examined in terms of compatibility and inconsistency between each other.

The gestational week, fetal birth weight, and neonatal intensive care requirement of the patients whose pregnancy and delivery results were available were recorded.

\section{Statistical Analysis}

For proper statistical analyses, Windows-based SPSS 24.0 statistical analysis program was used (SPSS Inc., USA). To determine whether they were normally distributed or not, variables were examined via visual (histograms, probability plots) and analytical methods (Shapiro-Wilk's test). Variables were descriptively specified as mean \pm standard deviation (X $\pm \mathrm{SD}$ ), mean difference between groups, 95\% confidence interval $(95 \% \mathrm{CI})$, median (minimum-maximum (min-max)), U value, frequency (n) and percentage $(\%)$.

\section{RESULTS}

In the study, we evaluated the fetal MRI indications and findings of seventy-three pregnant women. We analyzed the remaining forty-seven cases' delivery results by removing twenty-six pregnant women who did not have labor outcomes. The mean age of the patients was $28.1 \pm 6.2$ (Table 1).

Of the fetuses evaluated ultrasonographically before MRI, forty (54.8\%) of them had intracranial findings, fourteen $(19.2 \%)$ had gastrointestinal system findings, and six $(8.2 \%)$ had placental invasion anom-
Table 1. Descriptive analyses of values regarding the mothers and the babies

\begin{tabular}{lc}
\hline $\begin{array}{l}\text { Characteristics of Mothers and } \\
\text { Babies }\end{array}$ & $\begin{array}{c}\text { Pregnant } \\
\text { women }\end{array}$ \\
\hline Age (year) $(\mathbf{n}=\mathbf{7 3})$ & $28.1 \pm 6.2$ \\
Week of birth $(\mathbf{n}=\mathbf{4 7})$ & $38.3(28-41)$ \\
\hline Birth weight (g) & $2913.3 \pm 761.4$ \\
$\begin{array}{l}\text { Postpartum with mother, } \\
\text { breastfeeding, } \mathbf{n}(\%)\end{array}$ & $24(51.1 \%)$ \\
$\begin{array}{l}\text { Neonatal intensive care, } \mathbf{n}(\%) \\
\text { Intrauterine ex fetus, } \mathbf{n}(\%)\end{array}$ & $22(46.8 \%)$ \\
\hline
\end{tabular}

Data are shown as mean \pm standard deviation or median (minimum-maximum), $\mathrm{n}$ (percent).

alies. Five $(6.8 \%)$ of the cases were examined by MRI for the genitourinary system, four $(5.5 \%)$ for the spinal cord and vertebra, two (2.7\%) for cardiorespiratory system findings, and two $(2.7 \%)$ for head and neck masses. (Fig. 1).

In our study, the ultrasonographic findings of fiftyfive cases were confirmed with MRI findings. In eight cases, most of which were intracranial pathologies, additional findings were detected by MRI.

Of the seventy-three fetuses undergoing fetal MRI examination; Intracranial anomalies in thirty-six $(49.3 \%)$, placental invasion anomaly in four $(5.5 \%)$, gastrointestinal system anomalies in five $(6.8 \%)$ cases, genitourinary anomalies in six $(8.2 \%)$ cases, spinal cord anomaly in three $(4.1 \%)$ cases, a head or neck mass anomaly was detected in two patients $(2.7 \%)$. No apparent pathology was found in the MRI findings of

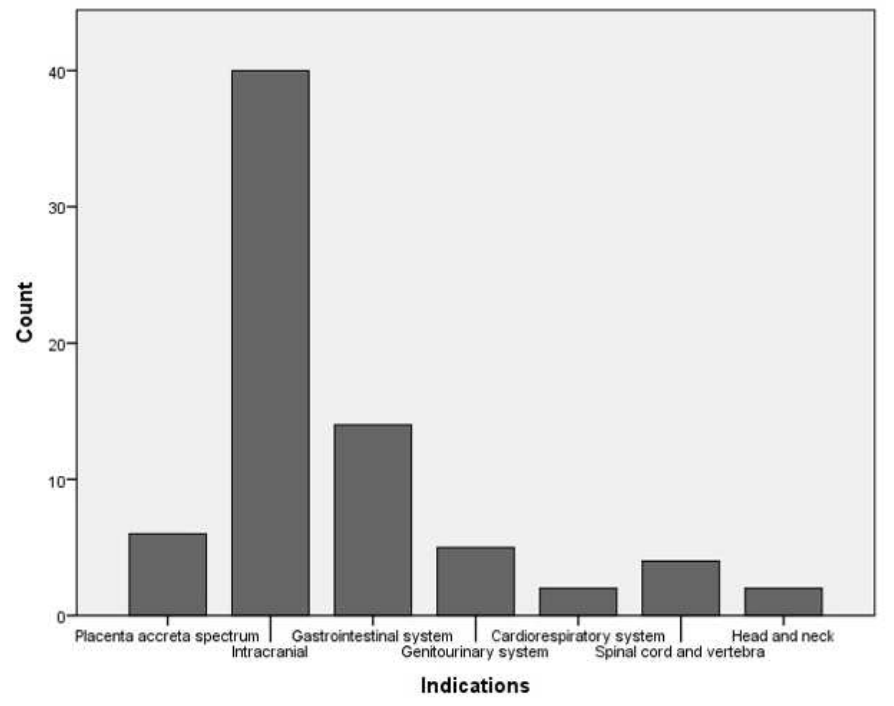

Fig. 1. The distribution of fetal MRI indications. 
seventeen (23.3\%) fetuses scanned (Fig. 2).

Four of the gastrointestinal system findings that we detected ultrasonographically and evaluated with MRI were tracheoesophageal fistula, and one of them was dilated bowel loops. In all of the five cases, MRI results were correlated with ultrasound findings. However, we found no consistent findings in any MRI evaluation of six fetuses with suspected esophageal atresia or tracheoesophageal fistula. We did not find any MRI finding of two cases with small stomach suspicion.

We planned further evaluation of sonographically detected intracranial neurological findings in forty patients. Ten fetuses had more than one intracranial finding. There were twenty-two fetuses with ventriculomegaly. We performed MRI to evaluate posterior fossa anomalies in six cases (mega cisterna magna, cerebellar hypoplasia, and vermian agenesis), twenty cases of cavum septum pellucidum, and corpus callosum anomalies, and one case of intracranial mass formation.

Fetal MRI findings were correlated with ultrasonography in thirty of forty cases, and MRI findings in four cases were natural. In two cases, we found ventriculomegaly ultrasonographically; Dandy-Walker Malformation was diagnosed with additional findings on MRI. In two patients with cavum septum pellucidum anomaly, we detected the congenital variation of cavum vergae with MRI. Additionally, lobar holoprosencephaly was observed in one patient with ventriculomegaly, and colposephaly was observed in another case. Additional findings to antenatal sonography were detected in six cases.

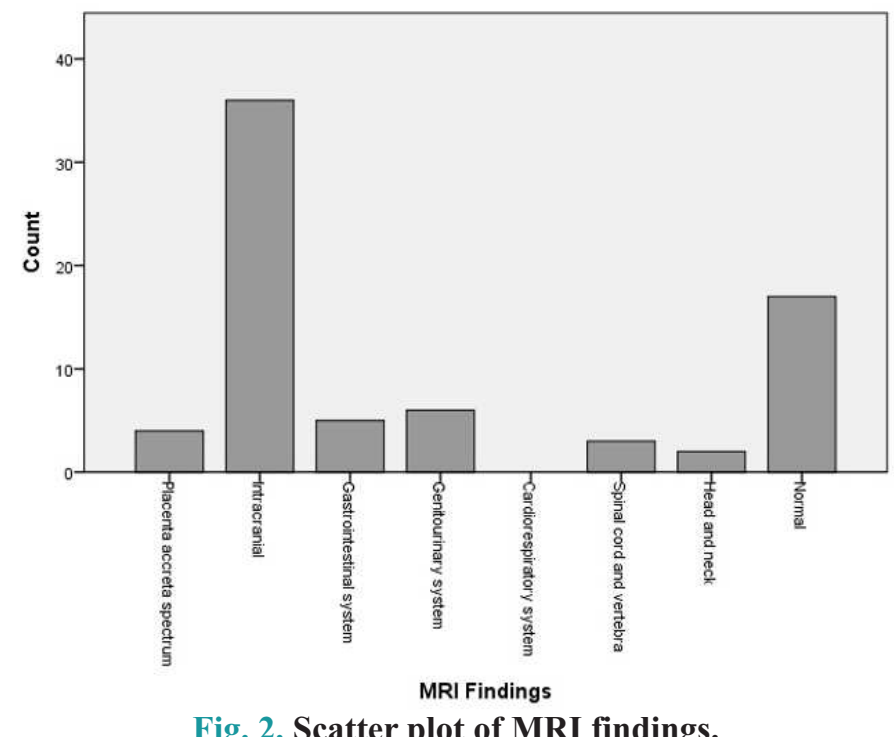

In the evaluation of six cases with suspected placental invasion anomaly in ultrasonography, four cases were found as placenta accreta in MRI.

Three fetuses were evaluated with MRI for renal agenesis, one fetus for multicystic kidney, and one fetus for hydronephrosis, and both images were correlated in all cases.

We found a suprarenal mass in a fetus we examined MR with a pre-diagnosis of pulmonary sequestration. MR imaging of a case with suspected diaphragmatic hernia was normal.

There was suspicion of sacrococcygeal teratoma in two fetuses and suspicion of spina bifida in one fetus, and MRI findings of all three fetuses were correlated. MR image of a fetus with suspicion of scoliosis and hemivertebra was natural.

We visualized the findings more clearly in MR images of both fetuses with oral and neck masses. The solid mass in the neck was compatible with teratoma.

\section{DISCUSSION}

Although ultrasonography is the basis of antenatal imaging today, fetal MRI is an increasingly crucial prenatal diagnosis method.

MRI has become an important screening method in recent years for multisystem evaluation of the fetus and diagnosis of congenital malformations [4, 5]. Magnetic resonance imaging (MRI) is most significant after the 20th week of gestation and provides more advantages than ultrasonography in evaluating the fetal brain. It is superior to ultrasonography in excluding CNS anomalies in a fetus with fetal malformation suitable for treatment. Standard gyral models, ventricular size, posterior fossa are best evaluated with MRI. Detailed observation of the cerebellar vermis is necessary for the diagnosis of Dandy-Walker malformation [5, 6 ]. The most common indication for fetal MRI is suspicion of central nervous system anomalies. Ventriculomegaly, posterior fossa, and corpus callosum anomalies are the three most critical cerebral causes for fetal MRI [2]. In our study, intracranial pathology suspicions constituted the majority of fetal MRI indications. Almost half of this group included fetuses with ventriculomegaly.

One of the essential points in the presence of ventriculomegaly is the presence of additional anomalies. 
Because isolated ventriculomegaly has a better prognosis, however, ultrasonography may be insufficient to detect additional anomalies. Therefore, MR imaging can be used for detailed examination $[2,7]$.

Studies in the literature show that; in detecting fetal anomalies, ultrasonography may be correlated with fetal MRI, and imaging with MRI may also reveal additional findings. A review stated that $65.4 \%$ of the ultrasonographic findings were confirmed with Fetal MR, and additional findings were found in $22.1 \%$ [8]. In our study, while the confirmation rate was $75.3 \%$, additional findings were detected in $10.9 \%$ of the cases.

Placental invasion anomalies are life-threatening serious obstetric problems that can lead to massive peripartum hemorrhage. Early diagnosis is essential because it enables preparing for a cesarean section in a planned way. The superiority of MR and ultrasonography over each other in these cases still being discussed, and there are publications in the literature stating that both imaging methods should be used in combination in suspected cases $[9,10]$. In our study, six cases with suspicion of placental invasion anomaly in ultrasonography were evaluated with fetal MRI, and invasion anomaly was observed in four of them. Maternal or fetal complications did not occur in any of these pre-diagnosed and planned cases.

MRI helps to identify lesions in the abdominal and cervical or spinal regions more efficiently by providing a wider field of view. Since only a small part of the lesion may be present in the acoustic window with ultrasonography, the entire anomaly and its anatomical relationships can be viewed more clearly with MRI. Also, MRI has become more valuable in anomaly diagnosis in recent years due to conditions that limit ultrasonographic evaluation, such as maternal obesity, excessive fetal activity, or technical problems [11].

\section{CONCLUSION}

Ultrasonography has a very effective and essential place in fetal anomaly screening. With the increasing technology, fetal MRI is also used in cases where ultrasonography is insufficient. Fetal MRI use and indications are not determined depending on many factors. Determining these indications is also essential in preventing unnecessary use in obstetric practice and de- termining the cost-effectiveness.

\section{Authors' Contribution}

Study Conception: BA, SSK; Study Design: BA, SSK; Supervision: BA; Funding: BA; Materials: BA, SSK, BŞK; Data Collection and/or Processing: BA, BŞK; Statistical Analysis and/or Data Interpretation: BA, SSK; Literature Review: BA, BŞK; Manuscript Preparation: BA, SSK and Critical Review: BA, SSK, BŞK.

\section{Conflict of interest}

The authors disclosed no conflict of interest during the preparation or publication of this manuscript.

\section{Financing}

The authors disclosed that they did not receive any grant during the conduction or writing of this study.

\section{REFERENCES}

1. Chalouhi GE, Millischer A-E, Mahallati H, Siauve N, Melbourne A, Grevent D, et al, The use of fetal MRI for renal and urogenital tract anomalies. Prenat Diagn 2020;40:100-9.

2. Patenaude Y, Pugah D, Lim K, Morin L, Bley S, et al; Diagnosetic Imaging Committee, Society of Obstetricians and Gynaecologists of Canada. The use of magnetic resonance imaging in the obstetric patient. J Obstet Gynaecol Can 2014;36:349-63.

3. Santos, XM, Papanna R, Johnson A,Cass DL, Olutoye OO, Moise KJ Jr, et al. The use of combined ultrasound and magnetic resonance imaging in the detection of fetal anomalies. Prenat Diagn 2010;30:402-7.

4. Griffiths PD, Bradburn M, Campbell MJ, Cooper CL, Graham $\mathrm{R}$, Jarvis D, et al.; MERIDIAN collaborative group. Use of MRI in the diagnosis of fetal brain abnormalities in utero (MERIDIAN): a multicentre, prospective cohort study. Lancet 2017;389:538-46.

5. Quinn TM, Hubbard AM, Adzick NS. Prenatal magnetic resonance imaging enhances fetal diagnosis. J Pediatr Surg 1998;33:553-8.

6. Sotiriadis A, Makrydimas G. Neurodevelopment after prenatal diagnosis of isolated agenesis of the corpus callosum: an integrative review. Am J Obstet Gynecol 2012;206:337.e1-5.

7. Robinson I. Fetal magnetic resonance imaging: a valuable diagnostic tool. Infant 2009;5:124-6.

8. Rossi A, Prefumo F. Additional value of fetal magnetic resonance imaging in the prenatal diagnosis of central nervous system anomalies: a systematic review of the literature. Ultrasound $\mathrm{Ob}-$ stet Gynecol 2014;44:388-93.

9. Mansour S, Elkhyat W. Placenta previa-accreta: do we need MR imaging? Egypt J Radiol Nucl Med 2011;42:433-42.

10. Mar WA, Berggruen S, Atueyi U, Sekhon S, Garzon SA, 
Knuttinen MG, et al., Ultrasound imaging of placenta accreta with MR correlation. Ultrasound Q 2015;31:23-33.

11. Tsai PJS, Loichinger M, Zalud I. Obesity and the challenges of ultrasound fetal abnormality diagnosis. Best Pract Res Clin Obstet Gynaecol 2015;29:320-7. 